\title{
GILEAD ESTÁ CERCA
}

\author{
GILEAD IS NEAR
}

\author{
Carmen AROCENA BADILLOS \\ Universidad del País Vasco / Euskal Herriko Unibertsitatea \\ carmen.arocena@ehu.eus
}

Resumen: Simone de Beauvoir definió a la mujer como el representante más claro de la alteridad, surgida de un proceso manipulatorio. La mujer ocupa cada una de las cuatro posiciones del cuadrado semiótico con el que Eric Landowski ha representado las diferentes maneras de relacionarse con el diferente. La serie televisiva El cuento de la criada las refleja y formaliza la relación de asimetría mediante oposiciones entre tipos de planos y la utilización reiterada de motivos figurativos.

Palabras clave: El cuento de la criada. Margaret Atwood. Serie de televisión. Semiótica. Feminismo. Análisis fílmico.

\begin{abstract}
Simone de Beauvoir defined women as the clearest representative of otherness, arising from a manipulative process. The woman occupies each of the four positions of the semiotic square with which Eric Landowski has represented the different ways of relating to the different. The television series The Handmaid's Tale reflects them and formalises the relationship of asymmetry through oppositions between types of planes and the repeated use of figurative motifs.
\end{abstract}

Key Words: The Handmaid's Tale. Margaret Atwood. The television series. Semiotics. Feminism. Film analysis. 


\title{
1. LA OTRA DE SIMONE DE BEAUVOIR
}

La historia de la humanidad, su cultura, su política, su estructura social, se puede entender como un recorrido sexuado que ha subordinado una mitad de la humanidad a la otra. Con suma claridad lo explicó Simone de Beauvoir cuando escribió en 1949 que:

lo que define de una manera singular la situación de la mujer es que, siendo como todo ser humano una libertad autónoma, se descubre (...) en un mundo donde los hombres le imponen que se asuma como lo Otro: se pretende fijarla en objeto y consagrarla a la inmanencia (Beauvoir, 1949: 9).

La mujer, entonces, no es el sujeto de la acción de la Humanidad, no está destinada a hacer sino a ser. Esta es la gran aportación de la filósofa existencialista que ha servido de inspiración al resto de las teóricas feministas porque en esta idea, que emparenta la relación hombre/mujer con la de amo/esclavo, todo su desarrollo posterior está contenido.

Por lo tanto, entendiendo la historia de la humanidad como una especie de programa narrativo, las mujeres desempeñan un rol muy limitado ya que la única posibilidad de convertirse en sujeto de una acción es mediante la unión con un único objeto, la maternidad, exclusiva aspiración permitida que ha grabado a fuego su evolución como ser humano:

\begin{abstract}
En este sentido, las mujeres, subyugadas a la obediencia del patriarcado, desconocían la esencia de su estado congénito y se sometían a las normas sociales que dictaban cuáles eran esos objetos de deseo a los que la naturaleza femenina debería aspirar y, por consiguiente, cuáles eran los límites (...) que cercaban los comportamientos correctos o incorrectos (Arocena, 2016: 449).
\end{abstract}

La semiótica estructural nos hace discernir que este deseo no surge de la nada, que un proceso previo enseña qué es lo que se debería anhelar. Por lo tanto, este deseo nace de un proceso manipulatorio que Greimas define como "una acción del hombre sobre otros hombres para hacerles ejecutar un programa dado" (Greimas, 1990: 251), en definitiva, un hacerhacer. Así se explica esta sumisión: 
de esta manera, el género femenino ha sido sometido a un proceso de manipulación - también previsto en toda narración - encarnado por un agente intangible, la tradicionalmente llamada sociedad patriarcal, que ha definido lo que las mujeres podían, debian, sabian y, en consecuencia, querian hacer (Arocena, 2016: 450).

Su recorrido narrativo se caracteriza entonces por la desunión con cualquier otro objeto. Para ello basta con fijarnos en las reclamaciones históricas de las luchadoras por el feminismo: no hay educación para ellas, no hay trabajo (salvo en escasas y paupérrimas ocasiones), no son seres libres, sino que deben ser tutelados por sus parientes masculinos o por el Estado, no deben salir del espacio doméstico salvo en justificadas ocasiones. Y aún hoy, muchas mujeres viven en un espacio semantizado en negativo.

Una serie de éxito de la cadena $\mathrm{HBO}$, El cuento de la criada, nos recuerda lo frágiles que son los lazos que convierten a la mujer en destinadora de su propio recorrido.

Por ello, Simone de Beauvoir habla de la otra para dar forma a esa relación de asimetría con el varón sin posibilidad de reciprocidad. Esa otra es la mujer, que en una sociedad patriarcal se ve arrojada a los márgenes de la sociedad, la cultura y las leyes. Y todo porque ha nacido en un cuerpo diferente, privilegiado, en cierto sentido, pero, causa también de desigualdades históricas que se utilizan para someter a las mujeres a la maternidad, reprimir su sexualidad y entregar el producto de su fuerza de trabajo, los hijos, al padre de la familia.

Encarnarnos en un cuerpo de hombre o de mujer tiene importantes consecuencias, entonces. Simone de Beauvoir defendió que aunque el cuerpo haya determinado el futuro de la mujer, no es la justificación de la desigualdad social. Añade que la biología no marca el destino de la mujer y que ese destino, que se sitúa en lo inmanente, anulando sus posibilidades de trascender, sólo es una imposición. De manera mucho más gráfica, en relación con este tema escribió: "no hay que deducir que sus ovarios la condenan a vivir eternamente de rodillas". La lucha de la mujer por la igualdad jurídica comenzó antes de que Beauvoir escribiera estas palabras; el combate por salir de la alteridad a la que ha sido condenada por el patriarcado continúa y una de las batallas a las que se tiene que enfrentar es la de la conquista de la soberanía sobre su cuerpo. 


\section{LA POSICIÓN DE LA MUJER EN LAS FIGURAS DE LA ALTERIDAD DE LANDOWSKI}

Las dos mitades de la Humanidad han establecido diversas maneras de entendimiento a lo largo de su recorrido. Eric Landowski (2007: 1949) ha representado en un cuadrado semiótico las diferentes maneras de relacionarse con el Otro, con el diferente, con la intención de "construir una gramática, un modelo teórico capaz, en lo posible, de recubrir la diversidad de los modos de relación concebibles entre un grupo cualquiera y lo que ese grupo se propone a sí mismo como su Otro" (Landowski, 2007: 19-49). A estas figuras de la alteridad les ha dado el nombre de segregación, exclusión, agregación y asimilación.

Revisando las fórmulas con las que el género humano ha gestionado su encuentro con el Otro, la mujer ha ocupado y ocupa cada una de las cuatro posiciones. Aunque Landowski es consciente de que cada uno de los términos "tiene su historia, cada uno está marcado por los empleos que de ellos se ha hecho en los discursos sociales, políticos, filosóficos u otros, que han fijado su valor" (Landowski, 2007:19-49) no podemos obviar la definición que de ellos se encuentra en los diccionarios. La primera figura es la segregación, que plantea una relación de "no conjunción", y que el diccionario de la RAE (Real Academia Española) entiende como la separación y la marginación de una o un grupo de personas por motivos sociales, políticos y culturales. Olvida mencionar la segregación por motivos biológicos que ha separado de la vida social, política, educativa y económica a la mitad de la humanidad.

La siguiente figura es la de la exclusión, es decir, "quitar a alguien o algo del lugar que ocupaba o prescindir de él o ello", la relación prototipo de la disjunción. Hay un ejemplo cristalino de exclusión de la mujer en algo tan propio como los derechos sobre su descendencia. En el caso de la filiación patrilineal los derechos de la madre sobre su progenie quedaban anulados simbolizados con la desaparición del apellido materno y en algunos países la exclusiva utilización del paterno. La desaparición de la figura de las madres biológicas en la gestación por medio de un "vientre de alquiler" es otro ejemplo válido.

En algunos países, el patriarcado ha conseguido adaptarse a los nuevos tiempos sibilinamente y hacer nacer la figura de la asimilación, que 
para Landowski es la figura representativa de la conjunción. El diccionario define "asimilación o asimilar" no como sinónimo de "integrar" sino de "asemejar o comparar" y plantea la posibilidad de coexistir pacíficamente. La pregunta es ¿con quién o con qué hay que comparar? No olvidemos que toda comparación examina dos términos: uno de ellos es el que no es cuestionado; el otro es que tiene que "asemejarse a". En definitiva, el Uno del que hablaba Simone de Beuvoir continúa convirtiéndose en la unidad de medida, en el referente ideal; la otra es la que debería llegar hasta allí.

La figura que ocupa el último ángulo del cuadrado de Landowski es la de la admisión, entendida como la no disjunción. "Admitir" es sinónimo de "aceptar" aunque otro de sus significados sea el de "asumir resignadamente un sacrificio, molestia o privación". De ninguna manera indica una situación de igualdad sino más bien una permanencia más o menos resignada en el espacio simbólico de la completa alteridad.

\section{LAS CRIADAS DE ATWOOD EN LA TELEVISIÓN}

Se habla del comienzo de una nueva ola feminista en la que las mujeres han comenzado a plantar cara al poder. El 5 de octubre, El País publicaba un artículo de Rosa Cobo (2018: s. p.), en el que sitúa el corazón de esta nueva ola en la lucha contra la violencia sexual que, en el último año, ha conseguido transformar un mal endémico de nuestra sociedad en un problema político ${ }^{1}$.

Lo interesante del artículo de Rosa Cobo (2018: s. p.) es que añade otras violencias relacionadas con un sistema neoliberal que convierte a la mujer en un objeto de consumo cuando escribe que:

la prostitución se ha convertido en el núcleo de una industria que incluso funciona como estrategia de desarrollo para algunos países. La pornografia, parte fundamental de la industria del sexo, y mecanismo principal de socialización masculina, difunde brutales mensajes de violencia contra las mujeres. Y el fenómeno de los vientres de alquiler se está configurando como una nueva forma de violencia que hace de la explotación reproductiva el eje de un nuevo negocio.

\footnotetext{
${ }^{1}$ Recordemos el nacimiento del movimiento Mee Too, las multitudinarias manifestaciones del 8 de marzo en todo el estado, hasta el movimiento Yo sí te creo, indignado por las sentencias judiciales y el atavismo del código penal.
} 
Ana de Miguel incide en esta cuando explicita que la estructura patriarcal se asienta y difunde por medio de la machacona creencia de que como ya hay igualdad, cualquier acción que realicen las mujeres es fruto de la libre elección, del consentimiento (De Miguel, 2015).

Por lo tanto, la prostitución, la pornografía y los vientres de alquiler son problemas políticos porque esclavizan, torturan y mantienen en la categoría de la otra beauvoiriana a la mujer debido a que en una sociedad neoliberal desaparece toda la empatía y solo importa el deseo y el derecho a satisfacerlo pagando con dinero.

En 1985, Margaret Atwood ya se había dado cuenta de estos problemas y publicó El cuento de la criada, exitosa novela que ha sido adaptada a diferentes medios: obra radiofónica, cinematográfica, serie de televisión e, incluso ópera. En 2017 en abril en Usa y en junio en España), MGM Television y Hulu produjeron su adaptación televisiva en diez capítulos, que consiguieron, entre otros premios, el Globo de Oro a la Mejor Serie Dramática. En ese mismo año comienza a viralizarse el hashtag "mee too" contra el acoso sexual en la industria cinematográfica norteamericana. En España, en 2017 ocurre otra cosa significativa: el Comité de Bioética de España publicó un informe sobre los aspectos éticos y jurídicos de la maternidad subrogada y su conclusión fue la del rechazo a esta práctica por entender que dicho contrato es contrario a la dignidad de la mujer ya que permite que su cuerpo se convierta durante nueve meses en mero instrumento para satisfacer los deseos de otros. La serie televisiva no pudo llegar en un momento más adecuado.

\subsection{El no-tiempo / el presente}

El cuento de la criada nos habla de mujeres que viven de rodillas en una sociedad en la que el poder político ejecuta sus deseos por medio de la represión militar, justificado por una actitud religiosa que no nos resulta muy lejana. Por ello, funciona como un espejo que representa una realidad que no es ficción para muchas mujeres.

La acción se desarrolla en la república de Gilead en un futuro no muy lejano, anteriormente conocida por Estados Unidos que, tras un golpe de estado, se ha convertido en una sociedad teocrática fuertemente militarizada en la que todas las mujeres han dejado de ser seres libres e 
iguales. Por ello, este texto funciona como un espejo que consigue que casi todas las figuras de la alteridad se puedan rastrear. En Gilead las mujeres son clasificadas en función de su capacidad reproductora. La segregación se encuentra en las mujeres no fértiles, separadas del resto en las colonias, destinadas a trabajos forzados en un lugar insalubre que no deja de recordar a los campos de exterminio nazis. La exclusión adopta la figura de las criadas, esclavas sexuales, cuya función es la de proporcionar hijos a los teócratas que disponen de sus servicios. En esta sociedad son admitidas las esposas, que asumen con resignación su privación de cualquier expectativa vital a cambio de ciertos privilegios. No hay ningún caso de inclusión porque en este mundo de ficción la frontera que separa a ambos sexos está claramente delimitada.

En ningún momento se da ninguna pista de cuándo suceden los hechos aunque se nos deja claro que no están muy alejados en el tiempo, que ese futuro es mucho más cercano de lo que nos gustaría. Además, lo interesante de la serie es que esa indeterminación temporal también engloba al pasado y al presente.
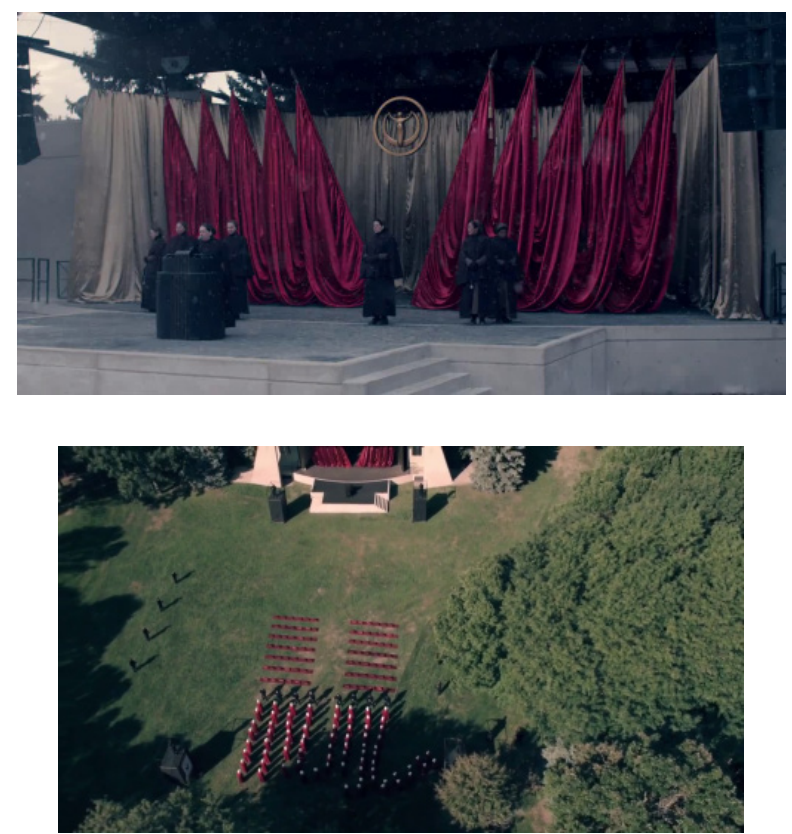

Figuras 1 y 2 

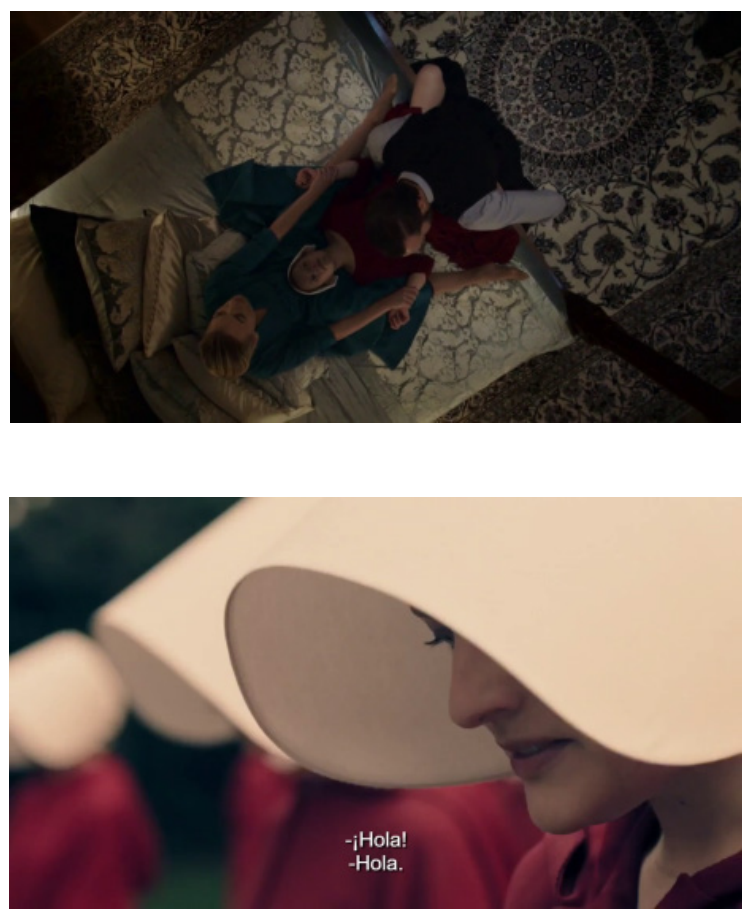

Figuras 3 y 4

Hay que tener en cuenta que Margaret Atwood ha confesado que todas las atrocidades que refleja su relato han ocurrido en algún lugar y en algún momento de la historia de la humanidad. Por ello, la serie recupera la estética nazi en cuanto a la utilización de emblemas que recuerdan la forma y colores de la cruz gamada [1], la disposición geométrica y lineal de las ceremonias colectivas [2], o la presencia de uniformes que rememoran a los usados por el ejército germano durante la II Guerra Mundial, probablemente uno de los momentos de la Historia de la Humanidad en los que el poder se ejerció con mayor crueldad. Todos estos motivos desarrollan el tema de la sumisión del individuo a los designios sociales. Por ello, se juega constantemente con la oposición entre planos cenitales [3] y primeros planos [4] que encarnan dos tipos de visión: una visión social, desde arriba, que juzga a la manera divina los comportamientos enfrentada a la visión cercana de los pensamientos, como única forma de expresión permitida.

Todo ello se complementa con la alternancia de dos tipos 
de estructuras narrativas: una estructura sin marcas en la que los acontecimientos se muestran directamente que se contrapone a una narración subjetiva en la que se comparten los pensamientos y sentimientos del personaje presentados como una especie de diario mental. Esta alternancia de voces se acerca a la apuesta narrativa que en su momento hizo la escritora canadiense reivindicando el derecho de la mujer a contar su propia historia.

\subsection{El oscurantismo de los tocados}

Por otra parte, el diseño de vestuario será el culpable de enlazar la vida de las mujeres de la nueva república norteamericana con momentos del pasado en el que vivían de rodillas: el oscuro mundo medieval, el puritanismo del siglo XVI o la vestimenta de algunas órdenes religiosas ya obsoleta. Un motivo figurativo altamente definitorio de esta situación es el de las tocas que llevan las criadas, inspiradas en momentos del pasado y en el enclaustramiento femenino.

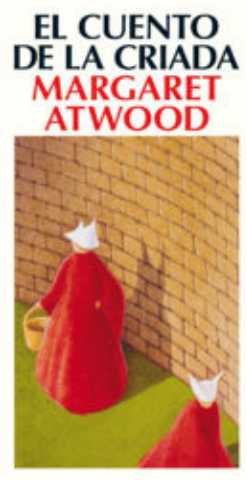

\& salamandra
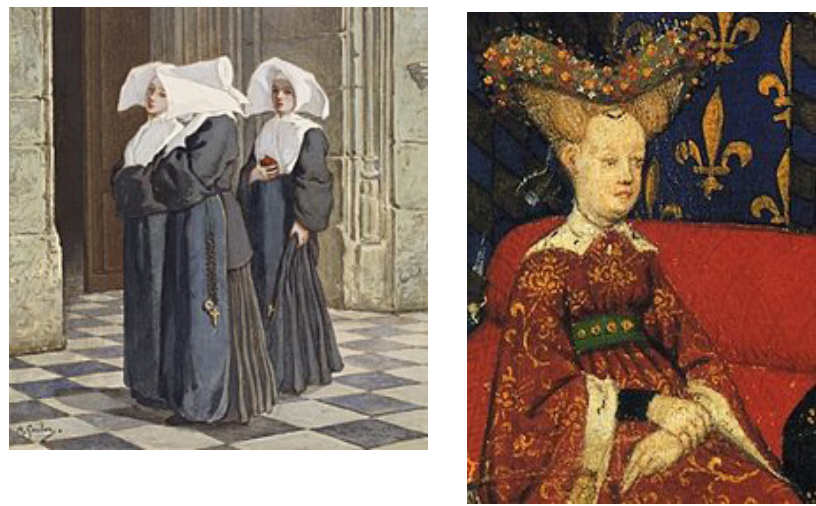

Figuras 5, 6 y 7 
Las portadas de la novela de Margaret Atwood siguen el mismo modelo de utilización del motivo figurativo de las tocas [5]. Podemos reconocer como inspiración las que llevaban las monjas de la orden de San Vicente de Paul [6], que dejaron de utilizarse en 1964. Y también algunos tocados medievales [7].

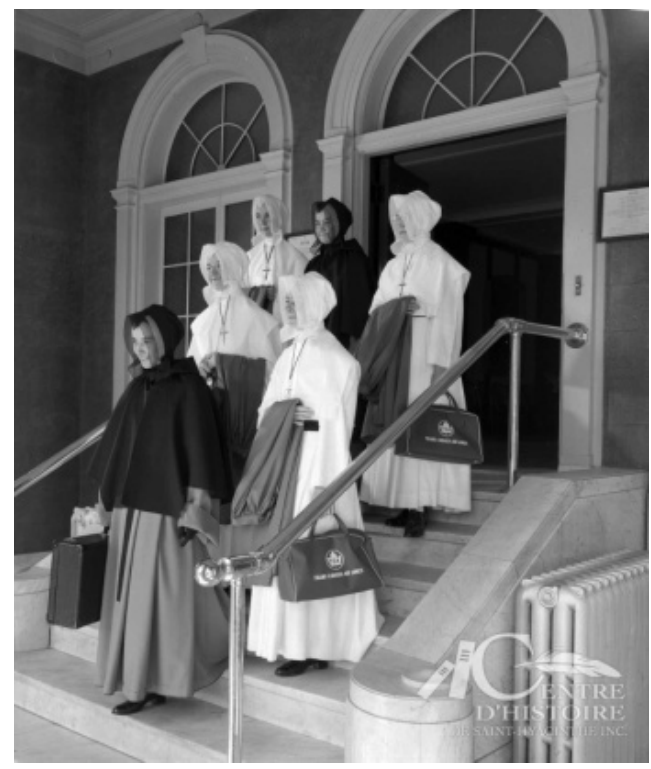

Figura 8

La iconología monacal servirá tanto para ordenar las posturas grupales de las criadas de la serie televisiva como para construir su tocado, más moderado e inspirado en otras órdenes religiosas, como sería el caso de las hermanas de la Caridad [8]. En la versión televisiva las tocas del uniforme de las criadas sirven para no ver, para no aplicar otra perspectiva que la que impone la república de Gilead.

En el relato, se imponen nuevos criterios sociales y religiosos para luchar contra pecados como el control de natalidad, el aborto, la promiscuidad sexual o inseminación artificial. Todos estos pecados han provocado un castigo divino: la esterilidad. Por ello, este patriarcado de ficción se fundamenta en principios relacionados con la moral religiosa. Para empezar, la función de las doncellas se justifica gracias al Génesis y a la historia de Abraham y su mujer estéril, que le ofreció a su criada para 
tener hijos a través de ella. No es casual que se retomen rituales religiosos como la repetición de mantras relacionados con la fertilidad, que recuerdan a las oraciones, o la sacralización del paso a criada. Si las religiosas se desposan con Cristo, las criadas lo hacen con el bienestar de una sociedad estéril. El destino de una criada es "encontrar la bendición", es decir, convertirse en vientre de alquiler.

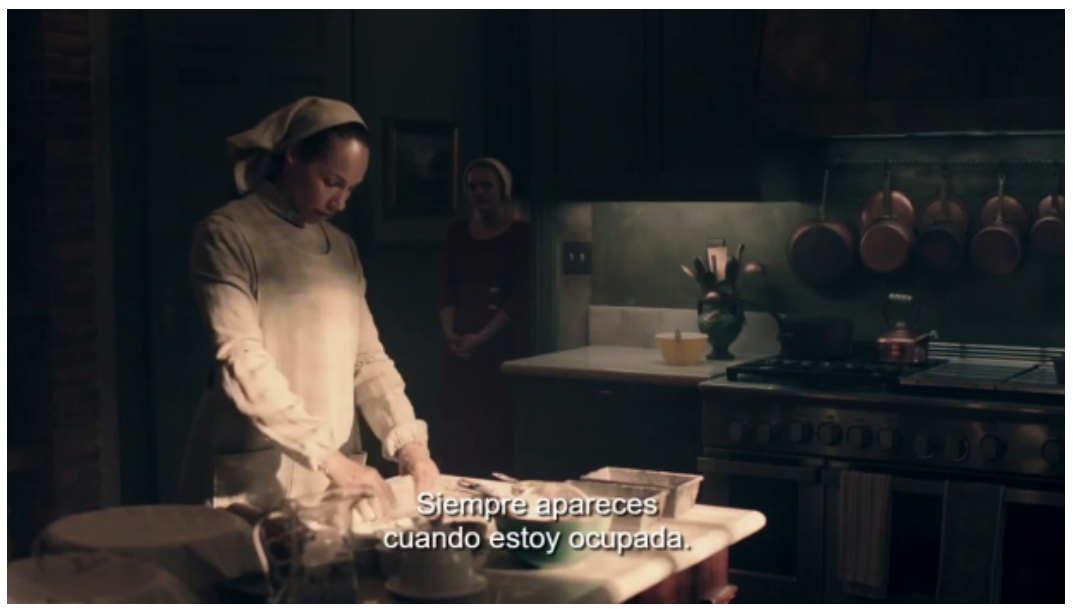

Figura 9

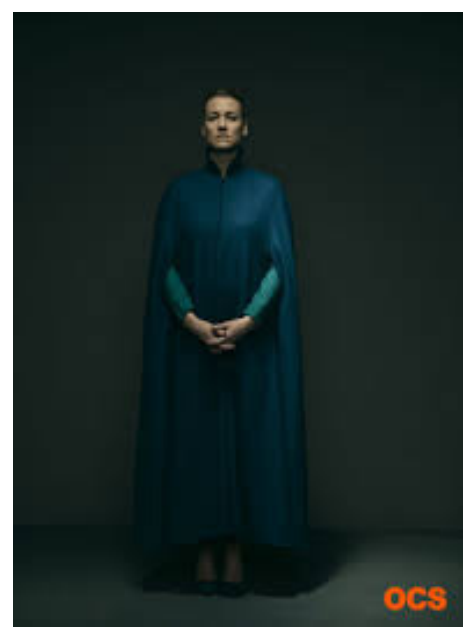

Figura 10 
No sólo las criadas sino también las "marthas", las mujeres encargadas de las labores del hogar, siempre recluidas en él, toman prestado el uniforme de algunas órdenes religiosas. [9]. Las esposas también van uniformadas. Sus vestidos tienen un aire de otros tiempos, como las capas, utilizadas durante la Edad Media [10].

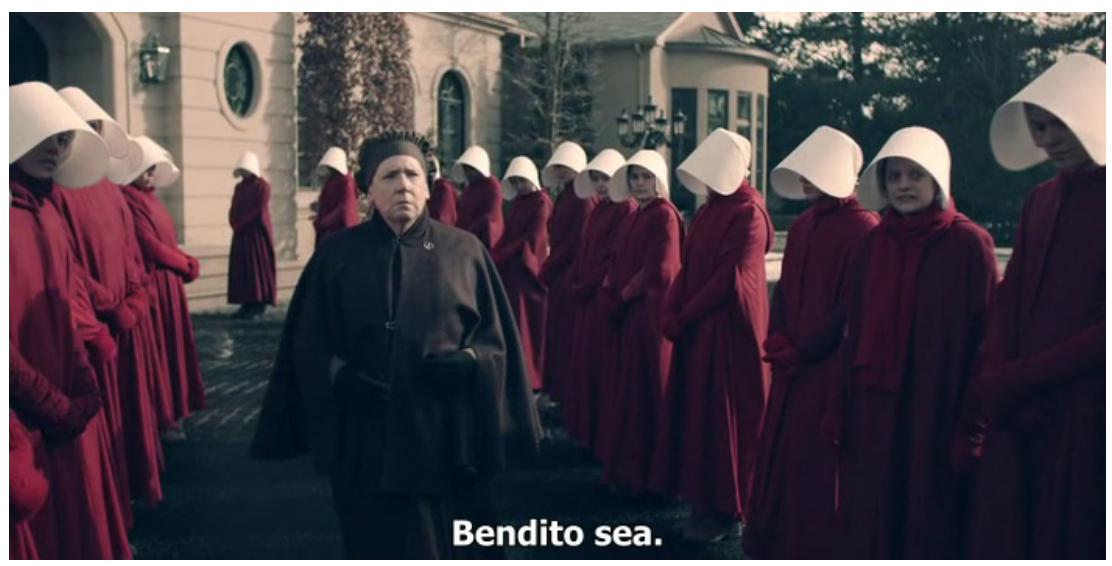

Figura 11

En definitiva, por medio del vestuario se hace referencia a un pasado lejano. Pero también a un pasado mucho más reciente. Basta con fijarse en la capa de Tía Lydia [11], más militarizada, que comparte una estética que no nos deja olvidar a la Alemania nazi.

\subsection{La simbología del color}

El argumento del filme nos habla de un país en el que sólo una de cada cien mujeres puede tener hijos. Son las criadas, que vestirán de blanco ya que su cuerpo es un templo de pureza y su destino es el de servir a Dios y a su país, engendrando para la clase social más alta y estéril. Una vez que se les haya adjudicado un hogar, el color de su vestimenta será el rojo. El resto de las mujeres también serán coloreadas según su función: las esposas (que sirven de representación social a los altos cargos del régimen) visten de azul, las marthas (las mujeres al servicio doméstico) de gris. El color agrupa a las mujeres en virtud de la función social que cumplen haciéndoles perder la individualidad que las caracteriza como 
seres humanos porque para la sociedad que nace tras el establecimiento de la república de Gilead, no lo son. La simbología de los colores nos enseña que el rojo es el color de la sangre y en la cultura occidental se relaciona con el pecado, el sacrificio y también el amor. Para las culturas orientales representa a los instintos más básicos y, en la India, es el color relacionado con la fertilidad. El blanco es el color de la pureza, aunque, para algunas culturas, también sea el de la muerte. Las doncellas visten de blanco para morir y llenarse de los valores de la nueva cultura. El azul que visten las esposas es el color que representa la estabilidad, pero también la melancolía y es el que designa a la aristocracia. Por último, el color gris es un no color, que denota la falta de relevancia de las marthas en el mundo descrito.

Todos los estereotipos de mujeres están representados en la serie, clasificados por colores y agrupados por su función: la casa de la que se ocupan las marthas, la calceta que entretiene a las esposas, la maternidad de la que son responsables las criadas, la enseñanza de los valores de la tradición y, por supuesto, el cuerpo femenino dedicado al disfrute del varón en las escenas que se desarrollan en el prostíbulo, el único lugar en el que el cuerpo de la mujer, que en sociedad se oculta, allí se muestra y ofrece.

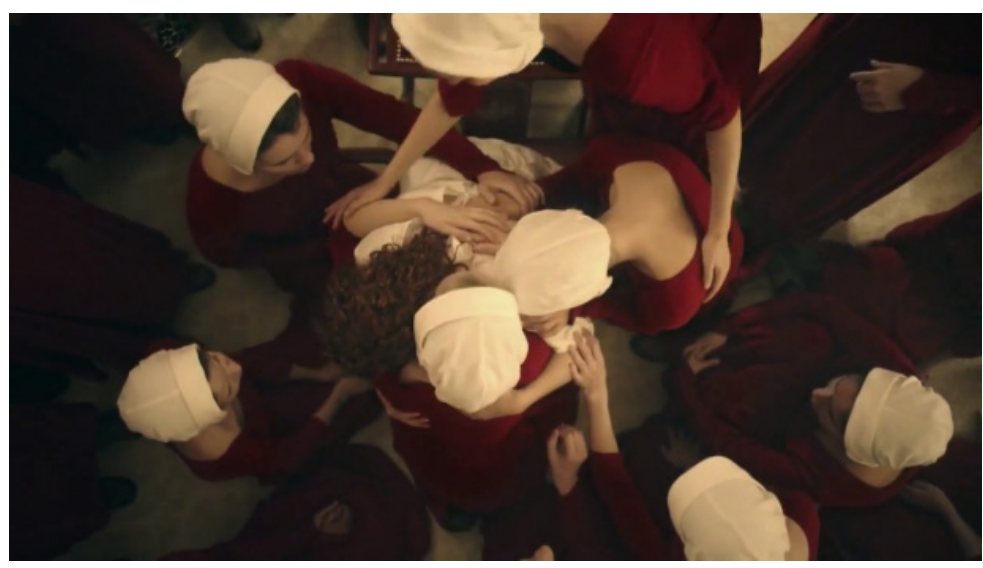

Figura 12 


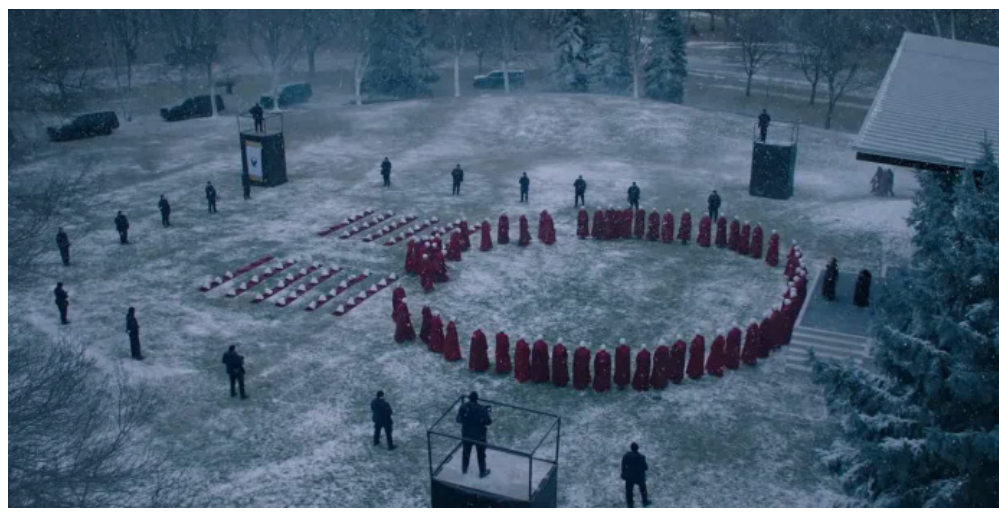

Figura 13

El cuento de la criada enfrenta a la sociedad y a la mujer. El relato será narrado en primera persona bajo la forma de un diario mental por una criada a la que se le prohíbe cualquier tipo de actividad intelectual. Estos momentos adoptarán la estructura visual del primer plano. Sin embargo, esta estructura cercana contrastará con la elección de planos cenitales o agudos picados que encarnan la mirada del varón creador, destinador y sancionador de sus destinos, que convierte a las criadas en motivos plásticos tendentes a la abstracción, es decir, en pura forma sin significado [12]. En muchos casos, los motivos plásticos adoptarán la forma de la circunferencia, sin principio ni final, eterno retorno [13].

\subsection{El no-tiempo / futuro}

El uniforme de las criadas ha sido adoptado por grupos feministas en Estados Unidos, Reino Unido, Irlanda y Argentina como símbolo de protesta para reivindicar el derecho al aborto, protestar contra la apropiación del cuerpo de las mujeres por parte del estado o contra decisiones de sus dirigentes varones. Con ello, estas activistas muestran que las mujeres seguimos siendo criadas y que la atemporalidad en la que está inserta la república de Gilead no es tal, se deja notar en un presente en el que se trafica con los cuerpos de las mujeres, entendidos como cuerpos plenamente accesibles y susceptibles de ser agredidos y comprados.

La advertencia de la serie de televisión es clara. Ojalá no tengamos que vestir con una túnica roja y una toca blanca ni siquiera para protestar. 


\section{REFERENCIAS BIBLIOGRÁFICAS}

AROCENA, C. (2016). "De paseo por la calle mayor. Matrimonio, soltería y violencia simbólica”. En Image et Violence, VV.AA., 447-453. Lyon: Le Grimh.

ATWOOD, M. (2017). El cuento de la criada. Barcelona: Salamandra.

COBO, R. (2018). "El feminismo hace historia". El País, 8 de octubre. Disponible en línea: https://elpais.com/sociedad/2018/10/05/ actualidad/1538749779_915230.html [19/03/2020].

DE BEAUVOIR, S. (1949). El segundo sexo. Los hechos y los mitos. Buenos Aires: Siglo XX.

DE MIGUEL, A. (2015). Neoliberalismo sexual. Madrid: Cátedra.

GREIMAS, A. J. y COURTÉS, J. (1990). Semiótica. Diccionario razonado de la Teoría del Lenguaje. Madrid: Gredos.

LANDOWSKI, E. (2007). Presencias del Otro. Ensayos de Sociosemiótica. Leioa: Servicio Editorial de la UPV / EHU.

Recibido el 2 de marzo de 2020.

Aceptado el 15 de abril de 2020. 